\title{
Comparison of the Level of Knowledge of High School Students Between the General System and Credit System Towards Burns First Aid
}

\author{
Abdulaziz A AlRabiah MD ${ }^{1}$, Afnan A AlMass MD*1, Turky Bn Duraihem² ${ }^{2}$ Fahad Alsuhibani ${ }^{2}$ and \\ Noura Ababtain ${ }^{2}$ \\ ${ }^{1}$ Department of Emergency medicine, College of Medicine, King Saud university, Saudi Arabia \\ ${ }^{2}$ College of Medicine, King Saud University, Saudi Arabia
}

*Corresponding author: Afnan A AlMass MD, Department of Emergency medicine, College of Medicine, King Saud university, Saudi Arabia

\section{ARTICLE INFO}

Received: 嵠 May 01, 2019

Published: 㓞 May 09, 2019

Citation: Abdulaziz AlRabiah MD, Afnan AA MD, Turky Bn D, Fahad A, Noura A. Comparison of the Level of Knowledge of High Schools Students Between the General System and Credit System Towards Burns First Aid. Biomed J Sci \& Tech Res 17(5)-2019. BJSTR. MS.ID.003068.

Keywords: First Aid; Burn; Knowledge; Student

Abbreviation: IFRC: International Federation of Red Cross and Red Crescent; CPR: Cardiopulmonary Resuscitation

\section{ABSTRACT}

Objectives: To evaluate the level of knowledge of high school students toward burns first aid and to measure the knowledge difference between high school students in the credits system and the general system.

Methods: The study is quantitative, observational and cross-sectional that was conducted by administrating translated Arabic version of Burns first aid measurement questionnaire. Five hundred and sixteen male and female high school students in Riyadh, Saudi Arabia were surveyed.

Results: Out of 516 questionnaires distributed. Most of the sample were male 373 (72.3\%), 44.6\% of participates are 17 years old, and Saudi (94.8\%). The study also showed that 356 students $(69 \%)$ had never attended previous training courses in first aid. The incidence of participants who reported knowing to use cool fresh water to reduce the temperature of the burn wound was $45 \%$ in credit system schools while $24 \%$ in general system schools. $6.2 \%$ of students in both two systems were indicating to stopping the fire and using the cool water in the first 15 minute. A lower knowledge level was significantly seen in a subgroup of female workers as well those who never attending training in first aid. The mean of general system schools' students' provided correct answers totaling 4.28 while 4.64 credit systems schools students'. Information source provided by school educational programs only $8 \%$ while mostly came from multimedia.

Conclusion: First aid knowledge of high schools' students' in both systems were significantly limited for burns management. The results were approximately higher in high school's credit systems. It will be needful to provide further training courses for students.

\section{Introduction}

Burns are considered one of the most common and destructive forms of trauma. Burn is a common occurrence at school, home and in other position [1]. Patients with significant thermal injury require immediate specialized care in order to minimize morbidity and mortality. Significant thermal injuries induce a state of immunosuppression that predisposes burn patients to infectious complications. Still complications of inhalation injury or result of burn wound sepsis are the causes of most deaths in severely burn-injured patients. Moderate to severe burn injuries requiring hospitalization [2].

Burns are considered one of the common problems in a developing country [3]. First aid management at the scene of the burn accident is one of initial management of burns is a significantly important step in treatment of burns. The simple and appropriate initial management of burns can reduce the depth of injury and subsequent complications including the need for surgery $[4,5]$. 
Noticed in the past few decades were improving in the survival rates for burn patients owing to forwards in latest medical care in specialized burn centers [2].

First aid is an assistance and provision of care for injury or illness, which could be provided usually by an ordinary person $[6,7]$. Basic knowledge of first aid and basic life support are essential. Since this age group spend most of their time in school and such injuries or unexpected illnesses that require immediate actions are very common in school age $[8,9]$. Reports from International Federation of Red Cross and Red Crescent Societies (IFRC) in the World First Aid Day on the 12th of September 2004, estimated that "tens of millions of lives are saved each year by first aid techniques applied by neighbors and bystanders to the victims of accidents or disasters" [10]. In Saudi Arabia, Public awareness of first aid and risk groups have not been satisfactorily tackled [11].

The concept of First aid was documented to be initially described by the surgeon Friedrich Von Esmarch (1823-1908). All over history, many different treatments have been using for the treatment of burns [12]. Regarding the difference between two systems because one of the differences between credit systems and general systems is credit systems have some courses related to social life, for example: Professional education course and Life skills and family education course. Moreover, students of credit systems need to do researches as homework to be able to succeed. The subjects of researchers from different fields. In addition, there is no study in our country to evaluate the difference between high school students in the credit system and the general system in their knowledge towards burns first aid (Figure 1).

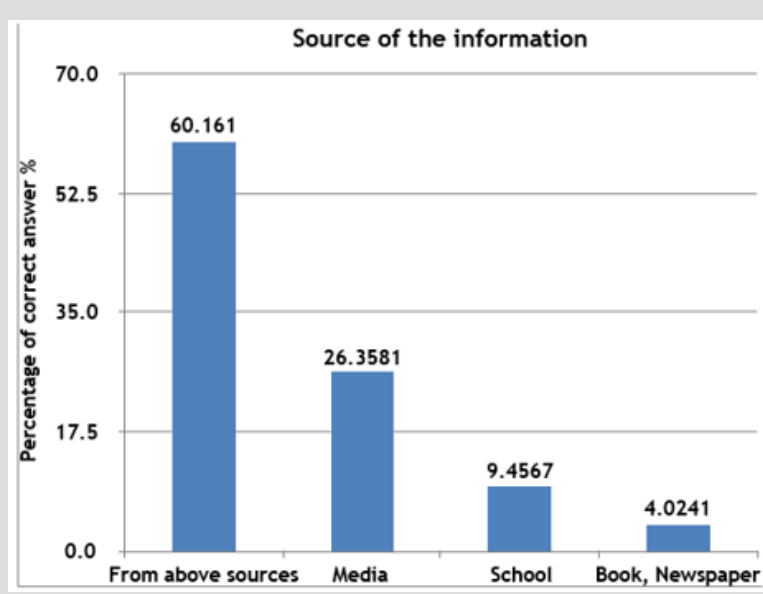

Figure 1: Source of the information.

\section{Methods}

\section{Study Design}

The study is quantitative, observational, cross-sectional. This study was undertaken at high schools in Riyadh city, the capital of Saudi Arabia. Riyadh public high school system in Riyadh is divided into four educational districts north, south, west and east. As of 2015, the number of registered high school students in credit system in Riyadh was 52,878 students, 27,088 male and 25,790 females. While the number of registered high school students in general system was 159,788 students, 78,171 male and 81617 females. The public-school education system in Saudi Arabia is based on separate male and female schooling on the Saudi Arabia jurisdiction. The high school education in Saudi Arabia made of three levels: first, second, and third. The data were collected from January 2019 to February 2019. We have distributed paper questionnaires to students. We were targeting all students' males and females. Excluding International community high schools' students.

\section{Sampling Technique}

We were collecting data randomly using systematic random sampling technique. Two high schools according educational districts, north, east, south and west. One high school of credit system and another of general system.

\section{Questionnaires}

The data was collected by distributing the questionnaires to the students without a fixed time. We translated, adapted and validated our questionnaire (Burns first aid measurement) [2] by using clear and user-friendly guidelines for translation and cultural adaptation [13]. They state recommendations in the translation of scales to gain reliable and valid versions. First step: we translated the original scale into the Arabic language by using two independent translators whose mother language is Arabic. Both are fluent, well experienced in the cultures of the two languages, and they have a deep background in medical terms. Second step: we compared between the two translated versions, and then we adopted one final version from both. Third step: another two translators whose mother language is English translated back the new Arabic version to English.

They are fluent in English and Arabic languages, they have an exceptional knowledge about the cultures of both languages, and they are experienced in translating medical studies. Fourth step: we compared between both the two back-translations, as well between the two versions and the main instrument yielding the obtaining of our Burns first aid measurement. The questionnaire was paper and pen; it includes the sociodemographic (Age, gender, nationality, parents' education level, marital status, income, school category, and attend first aid course).

\section{Pilot Study}

We did a pilot study for logistics of data collection, suitability/ clarity of data collection tools and estimation of timing for data collection. The questionnaire was piloted on 30 subjects, answering the questionnaire took $2 \mathrm{~min}$ in average. The data from the pilot study was not included in the main study.

\section{Sample Size}

The sample size required $=400$ (200 for every group). The sample size was calculated by using the following formula $\mathrm{n}=\mathrm{N} /$ $\left(1+N * e^{2}\right)$

Where $\quad n=$ sample size

$\mathrm{N}=$ population size

$\mathrm{e}=$ margin of error $(5 \%)$ 


\section{Data Analysis Plan}

Data will analyze by using Statistical Package for Social Studies (SPSS 22; IBM Corp., New York, NY, USA). Continuous variables will express as mean \pm standard deviation and categorical variables will express as percentages. $t$ - test will be used for Continuous variables. Chi square test will be used for categorical variables. A p-value $<0.05$ will be considered statistically significant.

\section{Ethical Consideration}

We got the approval from the IRB committee in the department of family and community medicine in the College of Medicine, King Saud University, Riyadh, Saudi Arabia. Every participant received and signed an informed consent form which explained the purpose of the study and the right to withdraw at any time without any obligation toward the study team. Also, participants' anonymity is assured by not collecting identifying data, and all participants are anonymous. There are no incentives or rewards were given to participants.

\section{Statistical Analysis}

Data were analyzed by using Statistical Package for Social Studies (SPSS 22; IBM Corp., New York, NY, USA). Continuous

Table 1: Characteristics of the participants. variables were expressed as mean \pm standard deviation. Categorical variables were expressed as percentages. $\square$ - test and one-way ANOVA were used for continuous variables. Chi square test was used for categorical variables. Univariate and Multivariate were used to assess the risk factors. P value less than 0.05 was considered statistically significant.

\section{Results}

Out of 516 questionnaires distributed, 499 questionnaires submitted valid responses $(\geq 90 \%$ valid responses to the questionnaire items), making a response rate of $96.7 \%$. Credit system schools' students' were 258 (50\%) and 258 (50 \%) for general system schools students'. Two main compartments are addressed in the results section: demographic findings, knowledge of respondents about burn first aid in association with the first aid training status, and the source of first aid information as was addressed by the students. Table 1 describes the comparison of credit system and general system with age, gender, marital status, occupation, family income and place. Almost half of the students aged 17 years old with mean (4.48). One third of the students came from families with monthly income SR $(10,000$ - 20,000) (37.9\%). The study also showed that 160 (31\%) students had ever attended previous training courses in first aid.

\begin{tabular}{|c|c|c|c|}
\hline \multicolumn{2}{|c|}{ Characteristics of the participants } & Number & $\%$ \\
\hline \multirow{2}{*}{ Gender } & M & 373 & 72.3 \\
\hline & $\mathrm{F}$ & 143 & 27.7 \\
\hline \multirow{5}{*}{ Age } & $16 Y$ & 158 & 30.6 \\
\hline & $17 Y$ & 230 & 44.6 \\
\hline & $18 Y$ & 114 & 22.1 \\
\hline & $19 Y$ & 11 & 2.1 \\
\hline & $20 Y$ & 3 & 0.6 \\
\hline \multirow{2}{*}{ Nationality } & Saudi & 489 & 94.8 \\
\hline & Non Saudi & 27 & 5.2 \\
\hline \multirow{4}{*}{ Father education } & $<=$ Intermediate & 76 & 15.2 \\
\hline & Secondary & 148 & 29.7 \\
\hline & University & 183 & 36.7 \\
\hline & Postgraduate & 92 & 18.4 \\
\hline \multirow{4}{*}{ Mother education } & $<=$ Intermediate & 80 & 16 \\
\hline & Secondary & 151 & 30.2 \\
\hline & University & 220 & 44 \\
\hline & Postgraduate & 49 & 9.8 \\
\hline \multirow{4}{*}{ Income } & $<5000$ & 44 & 10 \\
\hline & $5000-10000$ & 87 & 19.9 \\
\hline & $10000-20000$ & 166 & 37.9 \\
\hline & $>20000$ & 141 & 32.2 \\
\hline \multirow{2}{*}{ School category } & General system & 258 & 50 \\
\hline & Credit system & 258 & 50 \\
\hline \multirow{2}{*}{ Ever attending training in first aid } & Yes & 160 & 31 \\
\hline & No & 356 & 69 \\
\hline
\end{tabular}


Table 2 describes the knowledge of the students about some items of the basic information in burn first aid, given their training status. The incidence of students who reported knowing to use cool fresh water to reduce the temperature of the burn wound was $45 \%$ in credit system schools while $24 \%$ in general system schools. $6.2 \%$ of students in two systems were indicating to stopping the fire and using the cool water in the first 15 minute and the percentage was same in both systems the general and credit. Table 3 shows demographic data differences revealed between high schools' general system and credit system. The results were approximately higher in high school's credit systems. In addition, the result shows age differences revealed $4.3 \%$ and $1.2 \%$ of general system students' their age 19 and 20 years old respectively while no one's above 18 years old in credit system. In both systems the majority of the students' parents had a university qualification.

Table 2: Frequency and percentage of the correct answer for ALL, General system, and Credit system.

\begin{tabular}{|c|c|c|c|c|c|c|c|}
\hline \multirow{3}{*}{ Item } & \multicolumn{2}{|c|}{ ALL } & \multicolumn{2}{|c|}{ General System } & \multicolumn{2}{|c|}{ Credit System } & \multirow{2}{*}{ P Value } \\
\hline & Number & $\%$ & Number & $\%$ & Number & $\%$ & \\
\hline & 178 & 34.5 & 62 & 24 & 116 & 45 & \\
\hline What is the best method for burn first aid? & 231 & 44.8 & 109 & 42.2 & 122 & 47.3 & 0.161 \\
\hline Best duration for cool water application? & & & & & & & 0.75 \\
\hline \multirow{3}{*}{$\begin{array}{c}\text { How to apply cool water in the cold weather and large } \\
\text { burn surface area? }\end{array}$} & 122 & 23.6 & 68 & 26.4 & 54 & 20.9 & \\
\hline & & & & & & & $0.013^{*}$ \\
\hline & 47 & 9.1 & 24 & 9.3 & 23 & 8.9 & \\
\hline It is necessary to cover the burn surface? & 315 & 61 & 155 & 60.1 & 160 & 62 & 0.74 \\
\hline \multirow[t]{2}{*}{ It is necessary to keep body warm? } & & & & & & & 0.729 \\
\hline & 228 & 44.2 & 119 & 46.1 & 109 & 42.2 & \\
\hline The best time point to give first aid for burn? & 164 & 31.8 & 83 & 32.2 & 81 & 31.4 & $0.015^{*}$ \\
\hline How to escape from building in fire? & & & & & & & $<0.001^{*}$ \\
\hline \multirow{2}{*}{$\begin{array}{l}\text { How to prevent and limit smoke get in the room in case } \\
\text { of fire? }\end{array}$} & 240 & 46.5 & 108 & 41.9 & 132 & 51.2 & \\
\hline & & & & & & & $<0.001^{*}$ \\
\hline \multirow{3}{*}{ How to escape from multiple floor building in fire? } & 412 & 79.8 & 204 & 79.1 & 208 & 80.6 & \\
\hline & & & & & & & 0.992 \\
\hline & 32 & 6.2 & 16 & 6.2 & 16 & 6.2 & \\
\hline $\begin{array}{l}\text { What would you do in the first } 15 \text { minute when provid- } \\
\text { ing first aid to burn victim due to fire? }\end{array}$ & & & & & & & 0.876 \\
\hline \multirow{2}{*}{$\begin{array}{l}\text { All the burn wound will heal by itself with using local } \\
\text { medication? }\end{array}$} & 331 & 64.1 & 155 & 60.1 & 176 & 68.2 & \\
\hline & & & & & & & $0.007 *$ \\
\hline
\end{tabular}

Table 3: Characteristics of the participants by school category.

\begin{tabular}{|c|c|c|c|c|c|c|}
\hline & & \multicolumn{2}{|c|}{ General system } & \multicolumn{2}{|c|}{ Credit system } & \multirow{2}{*}{$P$ value } \\
\hline & & Number & $\%$ & Number & $\%$ & \\
\hline \multirow{2}{*}{ Gender } & $\mathrm{M}$ & 194 & 75.2 & 179 & 69.4 & \\
\hline & $\mathrm{F}$ & 64 & 24.8 & 79 & 30.6 & $<0.001^{*}$ \\
\hline \multirow{5}{*}{ Age } & $16 \mathrm{Y}$ & 36 & 14 & 122 & 47.3 & \\
\hline & $17 Y$ & 119 & 46.1 & 111 & 43 & \\
\hline & $18 \mathrm{Y}$ & 89 & 34.5 & 25 & 9.7 & \\
\hline & $19 \mathrm{Y}$ & 11 & 4.3 & 0 & 0 & 0.057 \\
\hline & $20 \mathrm{Y}$ & 3 & 1.2 & 0 & 0 & \\
\hline \multirow{2}{*}{ Nationality } & Saudi & 235 & 91.1 & 254 & 98.4 & \\
\hline & Non Saudi & 23 & 8.9 & 4 & 1.6 & 0.97 \\
\hline \multirow{4}{*}{ Father education } & $<=$ Intermediate & 31 & 12.5 & 45 & 17.9 & \\
\hline & Secondary & 84 & 33.9 & 64 & 25.5 & \\
\hline & University & 85 & 34.3 & 98 & 39 & 0.66 \\
\hline & Postgraduate & 48 & 19.4 & 44 & 17.5 & \\
\hline \multirow{4}{*}{ Mother education } & $<=$ Intermediate & 45 & 18.1 & 35 & 13.9 & \\
\hline & Secondary & 71 & 28.5 & 80 & 31.9 & \\
\hline & University & 103 & 41.4 & 117 & 46.6 & 0.054 \\
\hline & Postgraduate & 30 & 12 & 19 & 7.6 & \\
\hline
\end{tabular}




\begin{tabular}{|c|c|c|c|c|c|c|}
\hline \multirow{4}{*}{ Income } & $<5000$ & 20 & 9.2 & 24 & 10.9 & \\
\hline & 5000-10000 & 39 & 18 & 48 & 21.7 & \\
\hline & $10000-20000$ & 86 & 39.6 & 80 & 36.2 & 0.588 \\
\hline & $>20000$ & 72 & 33.2 & 69 & 31.2 & \\
\hline \multirow{2}{*}{$\begin{array}{l}\text { Ever attending } \\
\text { training in first aid }\end{array}$} & Yes & 73 & 28.3 & 87 & 33.7 & \\
\hline & No & 185 & 71.7 & 171 & 66.3 & 0.195 \\
\hline
\end{tabular}

Table 4 shows gender differences revealed 4.48 of male participants and $4.40(\mathrm{p}<0.581)$ of female participants answered the survey questions correctly. The mean of students had ever attended previous training courses in first aid provided correct answers totaling 4.74 comparing to 4.33 of students had never attended ( $p$ general system schools students' provided correct answers totaling 4.28 while 4.64 credit systems schools students' $(\mathrm{p}<0.006)$. The Univariate logistic regression for risk factors of low knowledge show in Table 5. A lower knowledge level was significantly seen in a subgroup of female workers (0.010) as well those who never attending training in first aid $(\mathrm{p}<0.006)$ show in Tables $6 \& 7$. $<0.004$ ). In addition, the comparison of two systems The mean of tionnaire by characteristics of the participants.

\begin{tabular}{|c|c|c|c|c|}
\hline & & Mean\$ & SD & P value \\
\hline \multirow{2}{*}{ Gender } & M & 4.48 & 1.53 & \\
\hline & $\mathrm{F}$ & 4.4 & 1.41 & 0.581 \\
\hline \multirow{5}{*}{ Age } & $16 \mathrm{Y}$ & 4.5 & 1.55 & \\
\hline & $17 Y$ & 4.48 & 1.45 & \\
\hline & $18 \mathrm{Y}$ & 4.36 & 1.44 & \\
\hline & $19 Y$ & 4.45 & 2.07 & \\
\hline & $20 \mathrm{Y}$ & 4 & 2.65 & 0.916 \\
\hline \multirow{2}{*}{ Nationality } & Saudi & 4.47 & 1.49 & \\
\hline & Non Saudi & 4.3 & 1.61 & 0.566 \\
\hline \multirow{4}{*}{ Father education } & $<=$ Intermediate & 4.46 & 1.24 & \\
\hline & Secondary & 4.41 & 1.48 & \\
\hline & University & 4.6 & 1.53 & \\
\hline & Postgraduate & 4.29 & 1.57 & 0.419 \\
\hline \multirow{4}{*}{ Mother education } & $<=$ Intermediate & 4.34 & 1.25 & \\
\hline & Secondary & 4.45 & 1.49 & \\
\hline & University & 4.59 & 1.53 & \\
\hline & Postgraduate & 4.16 & 1.68 & 0.245 \\
\hline \multirow{4}{*}{ Income } & $<5000$ & 3.93 & 1.86 & \\
\hline & $5000-10000$ & 4.63 & 1.43 & \\
\hline & $10000-20000$ & 4.6 & 1.46 & $0.040^{*}$ \\
\hline & $>20000$ & 4.43 & 1.35 & \\
\hline \multirow{2}{*}{ School category } & General system & 4.28 & 1.54 & \\
\hline & Credit system & 4.64 & 1.43 & $0.006^{*}$ \\
\hline \multirow{2}{*}{$\begin{array}{l}\text { Ever attending training in } \\
\text { first aid }\end{array}$} & Yes & 4.74 & 1.49 & \multirow{2}{*}{$0.004^{*}$} \\
\hline & No & 4.33 & 1.48 & \\
\hline Overall score & & 4.46 & 1.5 & \\
\hline
\end{tabular}

Note: * Significant $\mathrm{p}$ value

$\$$ Out of 11 (Correct answer $=1$, Wrong answer $=0$ ) 
Table 5: Univariate logistic regression for risk factors 0f low knowledge.

\begin{tabular}{|c|c|c|c|c|c|}
\hline & & \multirow{2}{*}{ OR } & \multicolumn{2}{|c|}{$95 \% \mathrm{CI}$} & \multirow{2}{*}{ P Value } \\
\hline & & & Upper & Lower & \\
\hline \multirow{2}{*}{ Gender } & M & 1 & & & \\
\hline & $\mathrm{F}$ & 1.81 & 1.09 & 2.99 & $0.021^{*}$ \\
\hline \multirow{5}{*}{ Age } & $16 \mathrm{Y}$ & 1.43 & 0.13 & 16.15 & 0.774 \\
\hline & $17 \mathrm{Y}$ & 1.9 & 0.17 & 21.35 & 0.605 \\
\hline & $18 \mathrm{Y}$ & 1.78 & 0.15 & 20.44 & 0.643 \\
\hline & $19 \mathrm{Y}$ & 0.87 & 0.06 & 12.97 & 0.923 \\
\hline & $20 \mathrm{Y}$ & 1 & & & \\
\hline \multirow{2}{*}{ Nationality } & Saudi & 0.95 & 0.37 & 2.41 & \\
\hline & Non Saudi & 1 & & & 0.915 \\
\hline \multirow{4}{*}{ Father education } & $<=$ Intermediate & 1.18 & 0.57 & 2.45 & 0.659 \\
\hline & Secondary & 1.05 & 0.57 & 1.95 & 0.867 \\
\hline & University & 0.99 & 0.55 & 1.79 & 0.981 \\
\hline & Postgraduate & 1 & & & \\
\hline \multirow{4}{*}{ Mother education } & $<=$ Intermediate & 1.25 & 0.52 & 3.01 & 0.612 \\
\hline & Secondary & 1 & 0.46 & 2.16 & 0.992 \\
\hline & University & 0.85 & 0.41 & 1.77 & 0.66 \\
\hline & Postgraduate & 1 & & & \\
\hline \multirow{4}{*}{ Income } & $<5000$ & 0.62 & 0.27 & 1.39 & 0.241 \\
\hline & 5000-10000 & 0.61 & 0.32 & 1.16 & 0.133 \\
\hline & $10000-20000$ & 0.59 & 0.34 & 1.03 & 0.062 \\
\hline & $>20000$ & 1 & & & \\
\hline \multirow{2}{*}{ School category } & General system & 1.33 & 0.88 & 2.01 & \\
\hline & Credit system & 1 & & & 0.175 \\
\hline \multirow{2}{*}{$\begin{array}{l}\text { Ever attending training } \\
\text { in first aid }\end{array}$} & Yes & 1 & & & \\
\hline & No & 1.72 & 1.12 & 2.64 & $0.012^{*}$ \\
\hline
\end{tabular}

Note: * Significant $\mathrm{p}$ value.

Table 6: Multivariate logistic regression for the risk factors of low knowledge.

\begin{tabular}{|c|c|c|c|c|c|}
\hline \multicolumn{2}{|c|}{} & \multirow{2}{*}{ OR } & \multicolumn{2}{|c|}{ 95\% CI } & P Value \\
\cline { 3 - 5 } & M & 1 & Upper & 3.25 & \\
\hline Gender & F & 1.95 & 1.17 & & $0.010^{*}$ \\
\hline $\begin{array}{c}\text { Ever attending training } \\
\text { in first aid }\end{array}$ & Yes & 1 & 1.19 & 2.84 & $0.006^{*}$ \\
\hline
\end{tabular}

Note: * Significant $\mathrm{p}$ value.

\section{Discussion}

To our knowledge, this is the first study in our country to measure the difference between high school students in the credits system and the general system. Efficient management of burns is initiate with first aid [14]. Can be significantly minimize the severity and improve the survival of burns injury by appropriate first aid and initial treatment $[1,2]$. Regrettably, as result of lack of knowledge on appropriate first aid burn victims are risky to undesirable outcomes and wound infection [15]. A study was done in Saudi Arabia showed there is significantly difference between previously trained students and untrained students [11]. While in our study was the mean of students had ever attended previous training, courses provided correct answers totaling 4.74 comparing to 4.33 of students had never attended $(\mathrm{p}<0.004)$.

A study was conducted in New Zealand in 2006 to assess students' knowledge and attitude towards resuscitation showed poor theoretical knowledge of students and it showed that trained students have greater knowledge than their untrained counterparts. However, gender plays no role in the ability to provide resuscitation [16]. While in our study shows female and those students who never 
attended previous courses were had low knowledge of first aid. On the other a hand study was done in UK to evaluating knowledge of family members reported that socio-economical class, income and age had no significant relationship to the results of the survey [17]. Moving regionally to the eastern countries a study was done in Cambodia showed there is significant lack in knowledge of students about burn prevention and first aid and the study was surveyed on 420 students $[15,18]$. Another paper was conducted in Pune resulted in the knowledge of students regarding management of emergencies including burns were poor [18].

Comparing the results between general system high schools students' and students of credit systems would show the results were approximately higher in high schools credit systems and the students belonged to high school credit system has higher number of those had ever attending first aid course (33.7\%), at the same time $(28.3 \%)$ of general system high schools students'. Also, for those students who ever attending first aid course had got higher score than others in both systems. In addition, credit system students' younger than the others. There were similar surveys conducted in Vietnam [11] the results showed most information came from family media (42\%) followed the school (8\%). In our results show the information sources were mostly provided by media $26.4 \%$ and only $4 \%$ through book and newspaper. Besides that in their study reported that $69.1 \%$ would use cool fresh water, although in our study shows $45 \%$ in credit system schools while $24 \%$ in general system schools would use cool fresh water.

In Turkey, physicians and nurses often are not present at schools [3]. As well in our country the physicians and nurses are not present at schools. In most states in the US, it is required for teachers to know First aid and CPR [1]. The awareness of first aid in the general population and students have significant role to ensure self- rescue and to reduce the severity. Therefore, in order to improve the knowledge of first aid for burn among high school students', the coming points ought to be considered: The curriculum should be including first aid course for common injuries including burns and first aid courses should be deeming as one goals of health education in schools. Moreover, every once in a while, check knowledge and practical skills of students' for first aid [13].

\section{Conclusion}

First aid knowledge of high schools' students' in both systems were significantly limited for burns management. It will be needful to provide further training courses for students. The results were approximately higher in high school's credit systems. In addition, credit system students' younger than others. For those students who ever attending first aid course had got higher score than others in both systems. The information source provided by school educational programs only $8 \%$ in both systems. It is necessary to administrate further training courses for students.

\section{Limitations}

Our study was done in Riyadh city which restrict the generalization of the results to the whole population of Saudi Arabia. Also, the scales were self-assessment tools instead of interviewing-based measures.

\section{Acknowledgment}

We thank all the participating students for taking part in the survey. Additionally, we thank Ministry of Education for allowed us to distribute our survey.

\section{Financial support}

This research did not receive any specific grant from funding agencies in the public, commercial, or not-for-profit sectors.

\section{References}

1. Lam NN, Dung NT (2008) First aid and initial management for childhood burns in Vietnam-An appeal for public and continuing medical education. Burns 34(1): 67-70.

2. McManus WF, Goodwin CW, Mason AD, Pruitt BA (1981) Burn wound infection. Journal of Trauma - Injury, Infection and Critical Care 21(9): 753-756.

3. Ghosh A, Bharat R (2000) Domestic burns prevention and first aid awareness in and around Jamshedpur, India: Strategies and impact. Burns 26(7): 605-608.

4. Lam NN, Li F, Tuan CA, Huong, HTX (2017) To evaluate first aid knowledge on burns management amongst high risk groups. Burns Open 1(1): 29-32.

5. Rea S, Kuthubutheen J, Fowler B, Wood F (2005) Burn first aid in Western Australia - Do healthcare workers have the knowledge? Burns 31(8): 1029-1034.

6. Mobarak AS, Afifi RM, Qulali A (2015) First Aid Knowledge and Attitude of Secondary School Students in Saudi Arabia. Health 07(10): 13661378.

7. Bașer M, Coban S, Tașci S, Sungur G, Bayat M (2007) Evaluating Firstaid Knowledge and Attitudes of a Sample of Turkish Primary School Teachers. J Emergency Nurs 33(5): 428-432.

8. Joseph N, Narayanan T, Bin Zakaria S, Nair AV, Belayutham L, et al. (2015) Awareness, attitudes and practices of first aid among school teachers in Mangalore, South India. J Primary Health Care 7(4): 274-281.

9. Teshale AA, Alemu ZA (2017) Knowledge, Attitude and Practice of first aid and factors associated with practice among taxi drivers in Addis Ababa, Ethiopia. Ethiopian J Health Development 31(3): 200-207.

10. Cuttle, L, Pearn, J, McMillan, J R, \& Kimble, R M (2009) A review of first aid treatments for burn injuries Burns 35(6): 768-775.

11. Sousa VD, Rojjanasrirat W (2011) Translation, adaptation and validation of instruments or scales for use in cross-cultural health care research: a clear and user-friendly guideline. J Evaluation Clin Pract 17(2): 268-274.

12. Baker B, Amin K, Khor WS, Khwaja N (2015) Response to: Practice of first aid in burn related injuries in a developing country. Burns 41(8): 1893-1894.

13. Hamdiya A, Pius A, Ken A, Paa Ekow HW (2015) The trend of acute burns pre-hospital management. J Acute Disease 4(3): 210-213.

14. Parnell MM, Pearson J, Galletly DC, Larsen PD (2006) Knowledge of and attitudes towards resuscitation in New Zealand high-school students. Emerg Med J 23(12): 899-902. 
15. Davies M, Maguire S, Okolie C, Watkins W, Kemp AM (2013) How much do parents know about first aid for burns? Burns 39(6):1083-1090.

16. Hsiao M, Tsai B, Uk P, Jo H, Gomez M, et al. (2007) "What do kids know": A survey of 420 Grade 5 students in Cambodia on their knowledge of burn prevention and first-aid treatment. Burns 33(3): 347-351.

17. Devyani S Shinde, DVS S, R Shinde DS (2015) Original article: Knowledge of high School students in Pune about first aid and the effect of training on them Indian Journal of Basic and Applied Medical Research, 5(1): 556-559.

18. Alharbi MM, Horaib YF, Almutairi OM, Alsuaidan BH, Alghoraibi MS, et al. (2016) Exploring the extent of knowledge of CPR skills among school teachers in Riyadh, KSA. J Taibah University Medical Sci 11(5): 497-501.

\section{ISSN: 2574-1241}

DOI: 10.26717/BJSTR.2019.17.003068

Afnan A AlMass. Biomed J Sci \& Tech Res

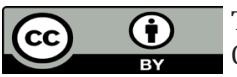

This work is licensed under Creative Commons Attribution 4.0 License

Submission Link: https://biomedres.us/submit-manuscript.php

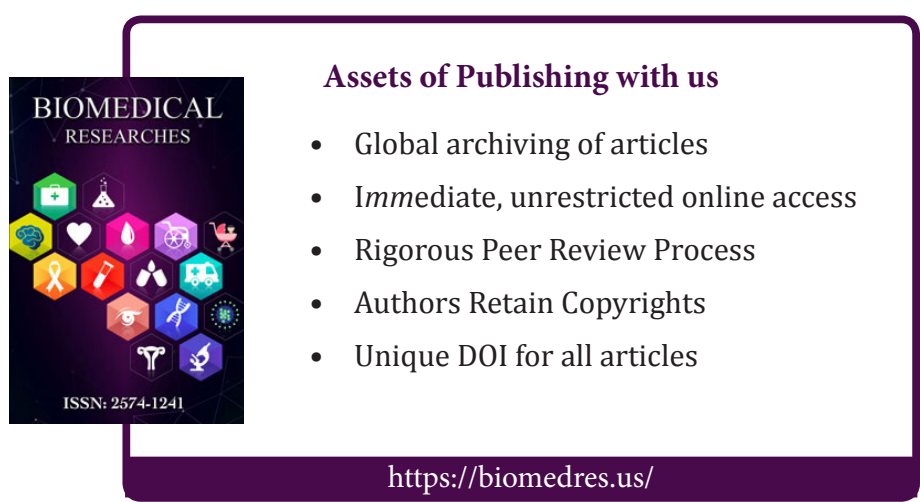

